\title{
Estratégias Locais para Tornar as Cidades mais Resilientes: o Caso de Garibaldi (RS)
}

\author{
MANFREDINI, Constance ${ }^{1}$ \\ SATTLER, Miguel Aloysio ${ }^{2}$ \\ ${ }^{1}$ Curso de Pós-graduação em Reabilitação Ambiental Sustentável Arquitetônica e \\ Urbanística-Reabilita, UnB, Brasília, Brasil. arqconstance@gmail.com \\ ${ }^{2}$ NORIE, UFRGS, Porto Alegre, Brasil. masattler@gmail.com
}

\section{Resumo}

O conceito de sustentabilidade traz consigo a preocupação com a sobrevivência da vida e com as próximas gerações. A literatura aponta para possíveis cenários futuros que impactarão as cidades gerando crises e expondo as suas vulnerabilidades. Neste contexto surge o discurso sobre a resiliência, que pode ser entendida como a capacidade, de uma comunidade exposta a riscos, de resistir, absorver e recuperar-se dos efeitos de um desastre, preservando e restaurando suas estruturas e funções essenciais. O objetivo deste trabalho é propor estratégias de caráter local para que as cidades possam se tornar mais resilientes, especialmente, com relação às mudanças climáticas e à escassez de combustíveis fósseis. A metodologia inclui revisão bibliográfica e aplicação dos conceitos contidos na obra "Resilient Cities: responding to peak oil and climate change" de Newman et. al (2009) em um estudo de caso. A cidade selecionada é Garibaldi, na Serra Gaúcha, que é uma comunidade com, aproximadamente, 30.000 habitantes. Os resultados apresentados constituem-se de recomendações que podem ser implementadas pelo Poder Público Municipal, bem como podem ser utilizadas como referencial para iniciar uma discussão sobre os temas abordados.

Palavras-Chave: resiliência; sustentabilidade; assentamentos humanos; mudanças climáticas; escassez de combustíveis fósseis.

\begin{abstract}
The concept of sustainability brings the concern about the survival of life and future generations. The literature points to possible future scenarios that will impact cities generating crises and exposing the vulnerabilities of the urban settlements. In this context arises the discourse on resilience, which can be understood as the ability of a community exposed to hazards to resist, absorb and recover from the effects of a hazard through the preservation and restoration of its essential basic structures and functions. The objective of this paper is to propose local strategies to turn cities more resilient, especially in relation to climate change and the scarcity of fossil fuels. The methodology includes literature review and the application of the concepts referred to in the work "Resilient Cities: responding to peak oil and climate change" by Newman et. al (2009) in a case of study. The city selected for the case of study is Garibaldi, in the Serra Gaucha, which is a small community with approximately 30,000 inhabitants. The results presented are recommendations that can be implemented by the municipal government, that can also be used as a benchmark to start a discussion on the topics covered.
\end{abstract}

Key-Words: resilience; sustainability; human settlements; climate chance; fossil fuel scarcity. 


\section{Introdução}

A resiliência pode ser entendida como a capacidade de um sistema, comunidade ou sociedade expostos a riscos, de resistir, absorver, acomodar-se e recuperar-se dos efeitos de um desastre, de forma oportuna e eficiente, através da preservação e restauração de suas estruturas essenciais e funções básicas (UNISDR, 2009). Newman et al. (2009) entendem e focam, em sua abordagem, que a cidade resiliente é aquela que tem a habilidade de responder à escassez de recursos naturais e às mudanças climáticas. Para os autores estes problemas estão conectados e devem ser analisados em conjunto.

O objetivo principal deste trabalho é propor estratégias de caráter local, para que as cidades possam se tornar mais resilientes, especialmente, com relação às mudanças climáticas e à escassez de combustíveis fósseis.

A metodologia utilizada neste artigo inclui revisão bibliográfica e aplicação dos conceitos identificados em um estudo de caso. Inicialmente, na etapa de revisão bibliográfica, são comentados possíveis cenários futuros e as crises que poderão impactar os assentamentos urbanos; são expostos conceitos referentes a resiliência e sua aplicação no âmbito das cidades; e são estudadas as ideias contidas na obra "Resilient Cities - Responding to Peak Oil and Climate Change" de Newman et al. (2009). $O$ estudo de caso se refere a uma cidade de pequeno porte, Garibaldi, que está localizada na Serra Gaúcha. As informações a respeito da cidade foram levantadas por meio da análise de relatórios técnicos, da legislação municipal e de observação local. O levantamento de dados expõe algumas das vulnerabilidades da cidade estudada e que constituem uma base para o desenvolvimento de propostas buscando torná-la mais resiliente. As propostas se pautam na aplicação dos conceitos de Newman et al. (2009), pelo fato de os autores tratarem do tema da inserção de resiliência nas cidades, abordando as mudanças climáticas e a escassez dos combustíveis fósseis de forma conjunta e integrada. Ao final do trabalho é apresentado um quadro com a síntese dos resultados obtidos.

\section{Resiliência}

\subsection{Os Cenários Futuros}

Os assentamentos urbanos estão sujeitos a riscos. O Fórum Econômico Mundial, em seu relatório "Global Risks 2015 - 10th Edition" destaca os 5 principais riscos globais em termos de impactos para o período de 2007 a 2015 (ver Figura 1). Como se pode perceber, a preocupação com o aumento do preço do petróleo e com as catástrofes ambientais aparecem na lista, confirmando a relevância destes eventos.

Newman et al. (2009) colocam que as cidades serão impactadas por crises que já vem sendo previamente anunciadas, com destaque para o declínio na produção de petróleo e para as mudanças climáticas. Os combustíveis fósseis são recursos não renováveis; ou seja, existem em quantidade finita e as suas reservas não são repostas, pelo menos não a uma velocidade comparável àquela da sua extração (ASPO - PORTUGAL, 2012). Roaf, Fuentes e Thomas (2009) estimaram que as reservas de petróleo estariam disponíveis por cerca de 40 anos e as de gás natural, por mais 65 anos.

Já, com relação às mudanças climáticas, um relatório da UN-HABITAT (2011), aponta que, nos últimos 50 anos, a média de temperatura global aumentou em $0,65^{\circ} \mathrm{C}$ e que durante o próximo século, a temperatura da superfície terrestre deverá aumentar entre 1 e $4^{\circ} \mathrm{C}$. O aumento de temperatura causará um efeito cascata, levando a um aumento severo na intensidade e frequência das tempestades, a condições de seca prolongada, ao aumento dos mares, associado à erosão e inundações em áreas costeiras, intensificação de enchentes, entre outros efeitos biofísicos.

\subsection{Resiliência e Cidades Resilientes}

No conceito de sustentabilidade, e, em especial, no de cidades sustentáveis, está presente a preocupação com a sobrevivência destas ao longo do tempo.

Segundo Santos (2010), os sistemas estão naturalmente expostos a perturbações, sendo que a sustentabilidade de um sistema depende de sua resiliência; ou seja, da sua capacidade de suportar essas perturbações e crises sem colapsar. Uma perturbação pode ser definida como um acontecimento relativamente discreto no tempo, geralmente proveniente do exterior (apesar de 
Figura 1: Os cinco principais riscos globais, em termos de impacto, de 2007 a 2015, com destaque para os eventos relacionados a combustíveis fósseis, setor energético e catástrofes climáticas

\begin{tabular}{|c|c|c|c|c|c|c|c|c|c|}
\hline & 2007 & 2008 & 2009 & 2010 & 2011 & 2012 & 2013 & 2014 & 2015 \\
\hline & $\begin{array}{l}\text { Queda de preços } \\
\text { de ativos }\end{array}$ & $\begin{array}{l}\text { Queda de precos } \\
\text { de ativos }\end{array}$ & $\begin{array}{l}\text { Queda de preços } \\
\text { de ativos }\end{array}$ & $\begin{array}{l}\text { Queda de precos } \\
\text { de ativos }\end{array}$ & Crises fiscais & $\begin{array}{l}\text { Fracasso do } \\
\text { sistema } \\
\text { finanoeiro }\end{array}$ & $\begin{array}{l}\text { Fracasso do } \\
\text { sistema } \\
\text { financeiro }\end{array}$ & Crises fiscais & Crise da água \\
\hline${ }^{\circ}$ & $\begin{array}{l}\text { Contenção da } \\
\text { gobalizaçăo }\end{array}$ & $\begin{array}{l}\text { Contenção da } \\
\text { globalizaçấo }\end{array}$ & $\begin{array}{l}\text { Contençäo da } \\
\text { globalizaçăo }\end{array}$ & $\begin{array}{l}\text { Contençẫo da } \\
\text { globalização }\end{array}$ & $\begin{array}{l}\text { Mudancas } \\
\text { climáticas }\end{array}$ & $\begin{array}{l}\text { Crises no } \\
\text { abastecimento } \\
\text { de agua }\end{array}$ & $\begin{array}{l}\text { Crises no } \\
\text { abastecimento } \\
\text { de água }\end{array}$ & $\begin{array}{l}\text { Mudancas } \\
\text { climáticas }\end{array}$ & $\begin{array}{l}\text { Propagaçāo rápida } \\
\text { eem massa de } \\
\text { odoenças } \\
\text { infecoosas }\end{array}$ \\
\hline 10 & $\begin{array}{l}\text { Guerras cavis e } \\
\text { entre naçōes }\end{array}$ & $\begin{array}{l}\text { Desaceleração } \\
\text { da economia } \\
\text { chinesa }\end{array}$ & $\begin{array}{l}\text { Pico do preço } \\
\text { do petroleo e } \\
\text { do gás }\end{array}$ & $\begin{array}{l}\text { Pico do preço } \\
\text { do petroleo }\end{array}$ & $\begin{array}{l}\text { Confilitos } \\
\text { geopoliticos }\end{array}$ & $\begin{array}{l}\text { Crises de } \\
\text { escassez de } \\
\text { alimentos }\end{array}$ & $\begin{array}{l}\text { Desequilibrios } \\
\text { fiscais crônicos }\end{array}$ & Crise da água & $\begin{array}{l}\text { Armas de } \\
\text { destruiçã̃o em } \\
\text { massa }\end{array}$ \\
\hline & Pandemias & $\begin{array}{l}\text { Pico do preço } \\
\text { do petroleo e } \\
\text { do gás }\end{array}$ & $\begin{array}{l}\text { Doencas } \\
\text { crônicas }\end{array}$ & $\begin{array}{l}\text { Doenças } \\
\text { crônicas }\end{array}$ & $\begin{array}{l}\text { Queda de precoss } \\
\text { de ativos }\end{array}$ & $\begin{array}{l}\text { Desequilibrios } \\
\text { fiscais crốnicos }\end{array}$ & $\begin{array}{l}\text { Difusåo de } \\
\text { armas de } \\
\text { destruiçąo em } \\
\text { massa }\end{array}$ & $\begin{array}{l}\text { Desemprego e } \\
\text { subemprego }\end{array}$ & $\begin{array}{l}\text { Confilito entre } \\
\text { naçס̄es com } \\
\text { consequências } \\
\text { regionais }\end{array}$ \\
\hline & $\begin{array}{l}\text { Impacto } \\
\text { causado pelo } \\
\text { preco do } \\
\text { petroleo }\end{array}$ & Pandemias & Crises fiscais & Crises fiscais & \begin{tabular}{|l|} 
Extrema \\
volatilidade dos \\
preços da \\
energia
\end{tabular} & \begin{tabular}{|l|} 
Extrema volatilida de \\
dos precosos da \\
energia dos \\
produtos ag icolas
\end{tabular} & $\begin{array}{l}\text { Fracasso das } \\
\text { adaptaçocs as } \\
\text { mudanças } \\
\text { climaticas }\end{array}$ & $\begin{array}{l}\text { Colapso da } \\
\text { infraestrutura de } \\
\text { informaçăo }\end{array}$ & $\begin{array}{l}\text { Fracasso das } \\
\text { adaptaçocs as } \\
\text { mudanças } \\
\text { climáticas }\end{array}$ \\
\hline
\end{tabular}

poder ter origem interna), que provoca disrupções e mudanças nos ecossistemas, comunidades, populações ou instituições, podendo, também, criar novas condições e oportunidades. As crises podem ser oportunidades de mudança, renovação e transformação, permitindo reconstruir a resiliência do sistema. Por vezes, quando um sistema se torna demasiado inflexível e resistente à mudança, apenas as crises tem o poder de desencadear novas soluções, respostas e relações, permitindo a adoção de uma nova trajetória.

Uma sociedade resiliente pode resistir a choques e ser reconstruída, se e quando necessário. Um sistema social resiliente deve ter a capacidade para antecipar e planejar o futuro. Os seres humanos dependem da resiliência para a sobrevivência (PRASAD et al., 2009). De uma forma simplificada, pode-se dizer que a resiliência é a capacidade de ser flexível. Os sistemas e os seus contextos mudam continuamente; então, está implícito no conceito de resiliência a capacidade de adaptação, de aprendizagem e de reestruturação contínua (SANTOS, 2009). A capacidade adaptativa se refere à habilidade de um sistema de se ajustar às condições internas e às circunstâncias externas (CARPENTER \& BROCK, 2008 apud SANTOS, 2009).

Segundo Satterthwaite (2011), se os riscos são plenamente entendidos, previstos e bem mapeados, as respostas que os eliminam ou os reduzem podem ser precisas. No entanto, este preparo é mais difícil quando os riscos são menos previsíveis; por exemplo, sobre quando irá ocorrer uma tempestade e qual será a sua intensidade. Com relação às mudanças climáticas há dois problemas adicionais. O primeiro é: com que frequência e intensidade os eventos climáticos extremos irão ocorrer e quem estará exposto a eles? O segundo, são as mudanças que aumentam os riscos e podem não causar desastres (por exemplo, a escassez de água fresca); ou, as mudanças que não causaram desastres no passado e podem contribuir significantemente para estes no futuro (por exemplo altas temperaturas, ilhas de calor e riscos de inundação, causados pelo aumento do nível do mar).

As cidades constituem sistemas altamente complexos, com propriedades físicas, organizacionais, sociais e econômicas. A resiliência urbana é a habilidade de um sistema urbano de resistir a certos níveis de estresse por meio de (ICLEI, 2011): (1) sistemas flexíveis, para absorver choques repentinos e retardar o início dos eventos; (2) distribuição de estresse em sistemas, evitando pontos de pressão individuais; (3) restauração da funcionalidade de uma maneira oportuna, para conter as perdas e evitar interrupções; (4) sistemas de substituição, caso uma grande perda de funcionalidade ocorrer; (5) sistemas que falham de forma segura, para evitar uma falha catastrófica; e (6) desenvolvimento da capacidade de identificar problemas e de lidar com eles, estabelecendo prioridades e mobilizando recursos para responder rapidamente, adaptar-se e seguir em frente. 
Os sistemas urbanos podem ser frágeis. Para resistir ao estresse, uma cidade, uma comunidade e seus cidadãos precisam entender quais sejam as suas vulnerabilidades. Por exemplo, se corredores de transporte, redes de energia e infraestruturas de comunicação estiverem em um local vulnerável a inundações ou tempestades, uma catastrófica falha do sistema poderá ocorrer. Entender as vulnerabilidades e riscos dos sistemas são a base para o bom desenvolvimento de planos de recuperação econômica e de emergência, e para construir comunidades sustentáveis (ICLEI, 2011).

\subsection{Os Sete Elementos Chave de uma Cidade Resiliente, segundo Newman et al. (2009)}

Newman et al. (2009) expõem a sua visão a respeito da cidade resiliente, propondo sete elementos chave, descritos a seguir.

\subsubsection{Cidade com Energias Renováveis}

As áreas urbanas deverão ser abastecidas com energias renováveis, tanto a nível urbano, bem como da edificação. O setor de transportes deve utilizar energias renováveis. Devem ser investigadas e utilizadas, sempre que possível, a energia solar, a eólica e a geotérmica.

\subsubsection{Cidade Neutra em Emissões de Carbono}

Todas as residências, vizinhanças e negócios deverão ter emissão zero de carbono. O processo para atingir o desenvolvimento urbano neutro em emissões de carbono consiste de três etapas: (1) redução do uso de energia, sempre que possível - em especial no setor da construção e de transportes; (2) utilização de fontes renováveis de energia, sempre que possível, tomando cuidado para que a produção desta não esteja contribuindo significativamente para a emissão de gases de efeito estufa; e (3) compensar o $\mathrm{CO} 2$ emitido por meio de compra de créditos de carbono, plantio de árvores ou outras opções renováveis.

\subsubsection{Cidade Distribuída}

As cidades deverão substituir os grandes sistemas centralizados de energia, água e tratamento de resíduos por sistemas de menor escala e sistemas baseados na escala da vizinhança. Deve ser incentivada a descentralização da produção de energia, tendo como base a produção em pequena escala. A produção de energia deve estar próxima de onde ela é consumida. Os benefícios incluem poupar energia através de um controle mais eficiente de sua produção; menor vulnerabilidade; $\mathrm{e}$ maior resiliência em relação a desastres naturais ou àqueles causados pelo homem. A mesma ideia deve ser adotada para os sistemas de abastecimento de água e de tratamento de resíduos.

\subsubsection{Cidade Fotossintética}

As cidades deverão ter potencial para aproveitar a energia renovável e produzir alimento e fibras localmente. A infraestrutura verde, geralmente, refere-se aos sistemas verdes e ecológicos; desde banhados, até florestas urbanas, que proporcionam uma série de benefícios para a cidade e seus moradores (água limpa, gestão e coleta de águas pluviais, moderação do clima e limpeza do ar, entre outros). Newman et al. (2009) propõem uma extensão deste conceito para o de "infraestrutura fotossintética". Desta forma, além do uso da energia do sol, do vento e do calor da terra, as plantações e matas, também, podem se habilitar a produzir energia renovável, em pequena escala. As áreas abertas, fora e dentro das cidades, serão espaços potenciais para produção de energia.

Segundo Newman et al. (2009), McDonough sugere que "cada telhado deveria ser fotossintético". Os topos das edificações poderiam ser utilizados para a coleta de água, para a inserção de telhados verdes e implantação de paisagismo, para a instalação de painéis fotovoltaicos ou para a geração de biocombustíveis.

Deve-se buscar produzir alimentos a nível local ou regional. Há bons exemplos, de comunidades urbanas (ou suburbanas) que criam espaços para hortas comunitárias, fazendas urbanas e fazem uso do conceito de paisagismo produtivo para satisfazer grande parte de suas necessidades de alimento. Deve-se, também, considerar a produção local de fibras e materiais de construção. Assim, haverá uma redução drástica nos gastos energéticos com transporte. Além deste benefício, as economias locais se tornarão mais resilientes frente às forças econômicas globais.

\subsubsection{Cidade Eco-eficiente}

As cidades e regiões deverão substituir os sistemas lineares por circulares ou fechados, onde quantidades substanciais das suas necessidades de energia e de materiais sejam supridas pelos fluxos de resíduos. 
As cidades possuem sistemas de metabolismo complexos, com inúmeros fluxos e ciclos. Elementos, tradicionalmente vistos como saídas negativas (ex: resíduos sólidos e líquidos) devem ser considerados entradas produtivas para satisfazer às necessidades humanas, inclusive em termos de energia. O novo paradigma de metabolismo urbano sustentável irá requerer profundas mudanças na maneira de pensar e planejar as cidades e regiões metropolitanas. Novas formas de cooperação e colaboração entre agências municipais, atores urbanos diversos e grupos formadores de opinião serão necessárias. Novas estruturas organizacionais e governamentais, ferramentas de planejamento e métodos deverão ser adotados; por exemplo, para mapear os fluxos dos recursos dentro da cidade e região.

\subsubsection{Cidade Identificada com o Local}

As cidades e regiões deverão entender que as energias renováveis são uma forma de fortalecer a economia local, alimentando uma alta qualidade de vida e criando um sentimento único e especial de comprometimento com o lugar.

Desenvolver a economia local proporciona uma série de vantagens, inclusive, aumentando a oferta de empregos. Encontrar caminhos para apoiar os empreendimentos locais é uma grande conquista em direção a uma comunidade menos dependente de petróleo. As municipalidades devem ter como prioridade desenvolver a economia local. No entanto, geralmente falham em reconhecer que a melhor abordagem é enfatizar a identidade do lugar.

Os gastos com energia - das municipalidades, companhias e indivíduos - representam um percentual significativo da economia. Produzir energia a partir do sol, do vento ou da biomassa, a nível local e regional, tem o poder de gerar empregos e rendimentos a partir de terras que podem estar sendo, economicamente, pouco produtivas.

Todos os esforços no sentido de tornar local a produção de energia, alimentos, materiais, assim como de fortalecer o desenvolvimento econômico dependerão da força da comunidade.

\subsubsection{Cidade de Transportes Sustentáveis}

As cidades, vizinhanças e regiões deverão ser planejadas para consumir energia com moderação. Quanto mais compacta uma cidade, menos os seus moradores dirigem, e, em consequência aumentam os deslocamentos a pé ou de bicicleta. A compacidade é um componente crítico para a redução da dependência do petróleo e das emissões de gases de efeito estufa.

Newman et al. (2009) ainda apontam os sete elementos para um transporte mais resiliente: (1) corredores de mobilidade, com trânsito mais rápido do que no resto da cidade; (2) centros densos ao longo dos corredores de mobilidade, buscando viabilizar um bom serviço; (3) áreas que permitam o deslocamento a pé e em bicicletas; o que significa um bom acesso aos meios de transporte não motorizados, especialmente nestes centros; (4) serviços que sejam acessíveis na maior parte do tempo, dia ou noite, minimizando a perda de tempo; (5) desativação gradual das freeways e gradual taxação de estradas, destinando os recursos para um fundo de trânsito, para melhorar as condições para pedestres e ciclistas, bem como para a implantação de medidas de traffic-calming; (6) melhoramento contínuo dos veículos, no sentido da redução de emissões gasosas, de ruídos e do consumo de combustíveis, desenvolvendo esforços no sentido da mudança para veículos elétricos; e (7) criação de um visão no governo local e regional em prol de um plano de transporte verde.

\section{Garibaldi: Aspectos Gerais}

O Município de Garibaldi, conhecido como a capital nacional do champanha, localiza-se no Estado do Rio Grande do Sul, integrando a Região Metropolitana da Serra Gaúcha. Situa-se a 110km de distância da capital do Estado, Porto Alegre e a $45 \mathrm{~km}$ de Caxias do Sul. Segundo o IBGE, o município possui $169,237 \mathrm{~km}^{2}$ e, de acordo com o Censo Demográfico de 2010, possui 30.689 habitantes, dos quais $88,67 \%$ residem na zona urbana e 11,33\%, na zona rural (Figura 2).

A economia do município está apoiada nas seguintes atividades: agropecuária, 6,54\%; indústria, 67,68\%; e serviços, $25,77 \%$. No setor industrial destacamse os segmentos metal mecânico; móveis e embalagens de madeira; alimentos e atividade vinícola (CIC \& PREFEITURA DE GARIBALDI, 2014).

Em 2008, foi aprovado o Plano Diretor em vigência (Lei Complementar $n .{ }^{\circ}$ 3). Este foi desenvolvido pela equipe da Prefeitura Municipal, com assessoria da Universidade de Caxias do Sul (UCS). Na lei, desenvolvida após o Estatuto da Cidade, estão expressos princípios relacionados ao tema de desenvolvimento sustentado. 
Figura 2: Localização de Garibaldi no RS e limites do município.

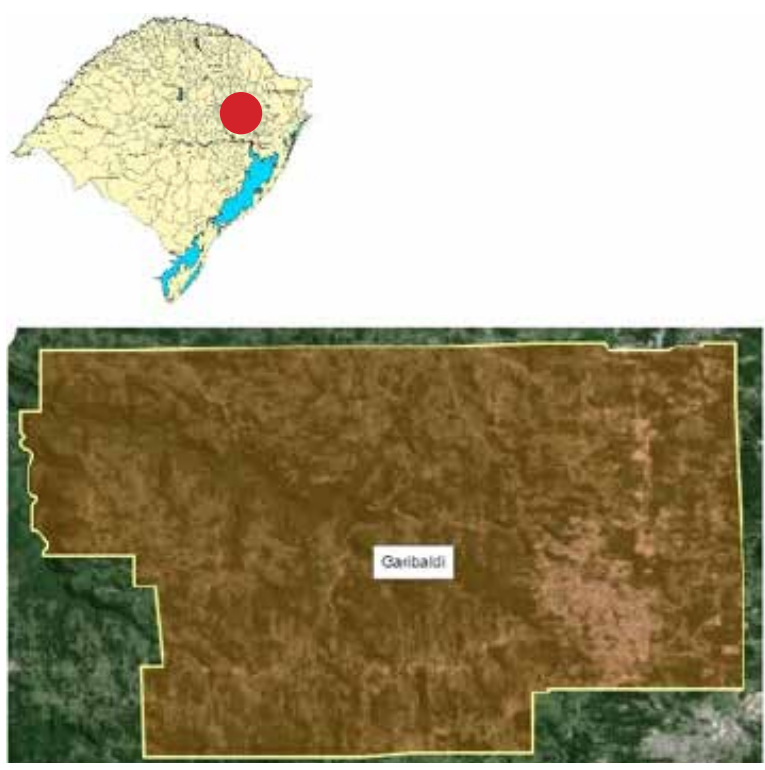

Fonte: Adaptado de Garibaldi, 2008 e Google Earth.

Tabela 1: Exemplos de Aplicação dos Conceitos de Cidade Resiliente de Newman et al. (2009) em Garibaldi-RS

\section{Garibaldi: Desenvolvendo Estratégias de Resiliência}

A partir da revisão bibliográfica e, em especial, dos sete elementos chave para a construção de uma cidade resiliente, segundo Newman et al. (2009), foram propostos exemplos de aplicação destes conceitos para a cidade de Garibaldi (RS). As propostas foram sugeridas a partir de um breve diagnóstico da situação do Município, elaborado a partir de revisão bibliográfica e observação local. Os resultados são apresentados na Tabela 1.

\section{Conclusão}

Ao longo do tempo os assentamentos urbanos são expostos e afetados por perturbações de ordens variadas, como: crises econômicas, escassez de água e devastações causada por tempestades ou vendavais, entre outros. A sustentabilidade de uma comunidade significa, em essência, a sua continuidade através das gerações. Contribuir para o aumento da resiliência é uma forma de

\begin{tabular}{l}
\hline DIAGNÓSTICO \\
\hline Cidade com Energias Renováveis \\
\hline Nos prédios públicos, a energia utillzada, de forma \\
geral, é a elétrica ou proveniente de gás liquefeito \\
de petróleo (GLP).
\end{tabular}

A maioria dos veículos leves da Prefeitura são movidos à gasolina.

\section{PROPOSTA}

Incrementar o uso de energia solar, através da instalaçăo de painéis fotovoltaicos, inicialmente, em alguns prédios públicos municipais. Nestas edificaçóes poderiam ser adotadas outras técnicas de arquitetura sustentável, podendo servir de edificaçóes modelo.

Utilizar combustiveis alternativos no transporte. Especificar, nas licitaçóes, sempre que possivel, a compra de veículos leves, alimentados a álcool ou elétricos. Incluir entre os critérios a serem avaliados a eficiência de desempenho do veículo.

Cidade Neutra em Emissóes de Carbono

Năo há uma política pública clara para a redução do consumo de energia nos prédios públicos ou particulares.

Năo há diretrizes claras ou obrigatoriedade legal para o plantio de árvores. Destacam-se algumas iniciativas, como: a existência de um viveiro municipal, que produz mudas para as áreas públicas, e campanhas de divulgaçăo da importância do plantio de árvores entre os alunos das escolas municipais.
Formular e programar o uso eficiente de energia; por exemplo, através de: projetos de retrotit na iluminação de prédios públicos existentes; nos projetos dos prédios públicos novos utilizar algum sistema de certificaçăo, como a do Procel; e introduzir, na legislaçăo, critérios que atentem para a eficiência energética.

Estimular o plantio de árvores; por exemplo, através da ampliaçăo do viveiro municipal e distribuiçăo de mudas para a populaçăo.

Elaborar instrumentos legais para estimular o plantio de árvores; por exemplo, definindo o número mínimo de árvores a serem plantadas nos passeios públicos. 


\section{Cidade Distribuida}

A Lel Municipal $n^{\circ}$. 3028/02, alterada pela Lei Municipal $n^{\circ} .4145 / 10$, exige que seja instalado um sistema individual de tratamento de esgoto, nos loteamentos onde năo há ETE - Estaçăo de Tratamento de Esgoto, antes de lançar os residuos na rede.

\section{Cidade Fotossintética}

Nåo há um levantamento preciso, ou cadastro e parques está a cargo da Secretaria de Esportes e Lazer.

Os telhados dos prédios públicos existentes, em sua grande maioria, năo estấo sendo aproveitados para a geraçăo de energia ou coleta da água da chuva.

O Plano Diretor, Lei Complementar $n^{\circ} 3 / 2008$, exige, para todas as edificaçóes, exceto as multifamiliares com até 4 economias, que seja implantado um sistema de coleta da água da chuva, para uso em atividades que năo necessitem de água potável.

Năo existem estudos sobre a produçăo de materiais de construçăo no municipio ou sobre a sua proveniência.
Seguir com o sistema de tratamento de esgoto distribuido, individual ou com uma ETE para cada loteamento. atualizado, das áreas públicas. A gestăo de praças

Realizar um levantamento e cadastro de áreas públicas. Estudar novas possibilidades para estas áreas, como, por exemplo, o uso de paisagismo produtivo e implantaçăo de hortas comunitárias.

Estudar alternativas de uso para os telhados das novas edificaçōes públicas e modificaçōes das já existentes (ex: coleta de água da chuva e instalaçăo de painéis fotovoltaicos, entre outros). Estender a obrigatoriedade de coleta de água da chuva, por exemplo, para as edificaçóes multifamiliares com menos de 4 economlas e em casos de retorma ou ampliaçăo de áreas.

Realizar um estudo para identificar a origem dos materiais de construçăo. Estimular a produçăo $e$ utilizaçăo de materiais locais, que podem ocorrer de diversas tormas, como: subsidios às industrias deste ramo instaladas no municipio e incentivos para reflorestamento que gerem madeira para consumo pela indústria da construçăo local; entre outros.

\section{Cidade Eco-eficiente}

Na cidade, há a coleta seletiva de resíduos urbanos. O lixo seco é reciclado; no entanto, o lixo orgânico é transportado até a cidade de Minas de Leão. Isto representa um elevado gasto energético de transporte, pois os residuos percorrem, aproximadamente, $170 \mathrm{~km}$ até 0 local de sua disposiçầo.

Garibaldi está inserida na regiáo da Uva e do Vinho. No município e na regiâo o setor vitivinícola é bastante significativo na economia, bem como está arraigado na cultura da populaçăo.

\section{Cidade Identificada com o Local}

Acredita-se que por ser uma cidade do interior, o senso de comunidade está bastante presente. Como exemplo, podem-se citar os inúmeros eventos comunitários, como a Festa ao Padroeiro, os Filos Italianos e o Torneio de Bisca. Cita-se, também, a organização da populaçăo em torno das associaçóes de bairro e dos clubes de măes.
Aproveitar os residuos orgánicos para a geraçăo de energia. Esta proposta pode ser estudada de forma integrada com os demais municipios da Regiáo Metropolitana da Serra Gaúcha.
Utilizar os residuos do setor vitivinicola, tais como o bagaço da uva, para a geraçăo de energia. Esta proposta pode ser estudada com os demais municípios da região.

Apoiar as organizaçóes e eventos comunitários já existentes, como forma de fortalecer os vínculos com o lugar. 


\begin{tabular}{|c|c|}
\hline \multicolumn{2}{|l|}{ Cidade de Transportes Sustentáveis } \\
\hline $\begin{array}{l}\text { O transporte utilizando bicicletas nâo é incluido } \\
\text { entre as estratégias de mobilidade urbana. }\end{array}$ & $\begin{array}{l}\text { Elaborar um plano de mobilidade, que inclua e } \\
\text { priorize o uso de bicicletas. }\end{array}$ \\
\hline $\begin{array}{l}\text { As condiçóes de trafegabilidade para os pedestres, } \\
\text { em geral, năo săo boas: em diversos pontos năo } \\
\text { há passeios públicos; vários passeios têm } \\
\text { inclinaçóes transversais inadequadas ou } \\
\text { apresentam degraus; năo há espaço suficiente } \\
\text { para a inserçăo de equipamentos urbanos; e as } \\
\text { calçadas, geralmente, săo estreitas; entre outros. }\end{array}$ & $\begin{array}{l}\text { Melhorar as condiçóes para os deslocamentos a } \\
\text { pé: executando passeios; regularizando os } \\
\text { passeios existentes; proporcionando arborizaçăo } \\
\text { que gere sombreamento; e implantando } \\
\text { dispositivos que proporcionem maior segurança } \\
\text { aos pedestres (faixas de pedestres elevadas, } \\
\text { orelhas nas esquinas, pisos diferenciados, etc.), } \\
\text { entre outros. }\end{array}$ \\
\hline $\begin{array}{l}\text { O Relatório para a Elaboraçăo do Plano Diretor } \\
\text { (GARIBALDI, 2008) apontava que, em grande } \\
\text { parte do perimetro urbano da época (dados de } \\
2006 \text { ), a densidade era de } 4 \text { habitantes/ha, ou seja, } \\
\text { uma densidade bastante baixa. As maiores } \\
\text { densidade se encontravam na área Central e em } \\
\text { bairros proximos (com densidade de } 30 \text { a } 40 \\
\text { hab/ha) e no Bairro Bela Vista (com mals de } 50 \\
\text { hab/ha). }\end{array}$ & $\begin{array}{l}\text { Atualizar dados e mapear as densidades, } \\
\text { estudando sua distribuiçăo na cidade. Planejar } \\
\text { as densidades em conjunto com o sistema de } \\
\text { transporte a ser adotado. Aumentar a densidade, } \\
\text { em algumas areas, para favorecer os } \\
\text { deslocamentos a pé e viabilizar o sistema de } \\
\text { transporte público. }\end{array}$ \\
\hline $\begin{array}{l}\text { Na maior parte da zona urbana é permitido o uso } \\
\text { misto do solo. Há restriçóes de instalaçăo de } \\
\text { algumas atividades em determinadas zonas, } \\
\text { predominantemente por questóes ambientais. Por } \\
\text { exemplo, na Zona da Bacia Santa Mónica năo săo } \\
\text { permitidos empreendimentos com qualquer } \\
\text { potencial poluidor (pequeno, médio ou alto). Na } \\
\text { Zona Residencial Vale dos Vinhedos e Residencial } \\
\text { Săo Deménace/Săo José săo permitidas somente } \\
\text { edificaçós residenciais. } \\
\text { Nas zonas industriais năo săo permitidos }\end{array}$ & $\begin{array}{l}\text { Implantar o uso misto do solo nas duas zonas do } \\
\text { Plano Diretor que săo exclusivamente } \\
\text { residenciais, com o intuito de diminuir as } \\
\text { distâncias de desiocamento. } \\
\text { Possibilitar a inserçăo de loteamentos } \\
\text { residenciais nas proximidades das zonas } \\
\text { industriais. }\end{array}$ \\
\hline DIAGNOSTICO & PROPOSTA \\
\hline os reside & \\
\hline
\end{tabular}

Fonte: Adaptado de Newman et al. (2009).

somar esforços no sentido de atingir alguns dos objetivos contidos no conceito de sustentabilidade. A resiliência urbana inclui a capacidade de ser flexível e de se adaptar aos cenários presentes e futuros para garantir a sobrevivência das cidades. Assim como o conceito de sustentabilidade é pauta recorrente no cotidiano e está sendo gradualmente introduzido no planejamento e construção das cidades, o conceito de resiliência deve trilhar o mesmo caminho. É necessária a adaptação das cidades, por meio do desenvolvimento de uma nova forma de pensá-la, seja por parte dos gestores públicos, como dos responsáveis pelo planejamento urbano e da sociedade em geral.

O objetivo principal deste trabalho foi o de propor estratégias de caráter local, para que as cidades possam se tornar mais resilientes, em especial com relação às mudanças climáticas e à escassez de combustíveis fósseis.

A revisão bibliográfica, realizada neste trabalho, apontou que diversos autores e organizações respeitadas expressam preocupação com eventos impactantes, como as mudanças climáticas e o pico do petróleo. Os impactos resultantes certamente afetarão as cidades, podendo gerar cenários futuros muito adversos. Diante desta situação, recomendam-se ações de adaptação das cidades, no intuito de minimizar os possíveis impactos negativos.

Foram apresentados exemplos de estratégias para acrescer o grau de resiliência das cidades, em 
especial, no que tange a adaptação às mudanças climáticas e à escassez do petróleo. Em adição foi feita uma aplicação em um estudo de caso: no município de Garibaldi, localizado na Serra Gaúcha. Constatou-se que não há políticas públicas claras direcionadas à introdução de resiliência, como um todo; no entanto, percebe-se que algumas iniciativas estão alinhadas com as estratégias descritas.

Newman et al (2009) apontam sete elementos chave na busca por cidades resilientes: cidade com energias renováveis; cidade neutra em emissões de carbono; cidade distribuída; cidade fotossintética; cidade eco-eficiente; cidade identificada com o local; e cidade de transportes sustentáveis. Dentro destes conceitos, pode-se citar, como exemplos positivos em Garibaldi: o uso do solo misto, em grande parte de seu território urbano; a exigência no Plano Diretor de captação da água da chuva; e o senso de comunidade e identidade com o local.

Contrapondo os pontos positivos, há uma série de vulnerabilidades e de medidas que poderiam ser tomadas para aumentar a resiliência da cidade. Sugere-se a adoção de estratégias como: incentivar o plantio de árvores; aproveitar os resíduos urbanos para a geração de energia; adotar medidas para a produção de alimentos e materiais de construção a nível local; utilizar energias renováveis nos prédios públicos; implantar estruturas para possibilitar o deslocamento em bicicletas; e melhorar as condições para os pedestres, entre outros.

Este trabalho gerou recomendações, a partir do estudo de caso, que podem ser adotadas para aumentar a resiliência de outras cidades com características semelhantes. De forma alguma se pretende esgotar a discussão sobre estes temas; limitamo-nos a dar um passo inicial de uma longa caminhada.

As recomendações geradas pautam-se em conteúdos de diversas áreas, exigindo uma abordagem multidisciplinar. Os assuntos abordados estão relacionados entre si e diversas estratégias têm condições de atender a mais de uma finalidade. O uso misto do solo reduz o número e distância das viagens, estimulando os deslocamentos a pé. Esta estratégia tanto contribui para a diminuição do consumo de combustíveis fósseis, como diminui a emissão de gases do efeito estufa, que são causadores das mudanças climáticas.
As estratégias propostas colocam o poder público no centro destas mudanças. Contudo, a adoção de uma postura voltada à resiliência deve envolver a sociedade como um todo. Constatou-se que algumas das estratégias poderiam ser adotadas em curto prazo e não exigem recursos públicos significativos; no entanto, outras necessitam de planejamento a médio e em longo prazo, bem como de recursos consideráveis.

O desafio na busca por cidades mais resilientes pode ter de enfrentar uma série de dificuldades, como: a compreensão dos desafios e a decisão de enfrentá-los, por parte de gestores e da sociedade; a falta de planejamento e de conhecimento sobre o assunto; a necessidade de adaptação da legislação e demais instrumentos legais; a complexidade de se lidar com temas multidisciplinares, com ações envolvendo profissionais e departamentos de áreas variadas; e a escassez de recursos financeiros, entre outros.

Recomenda-se que sejam desenvolvidos estudos no sentido de criar uma metodologia que possibilite a construção de cidades mais resilientes, que, com o auxílio de um plano de ação consistente, flexível o suficiente de modo a adaptá-lo a cenários futuros, tendo como agente central o poder público. Este plano deve conter, entre outros, objetivos expressos com clareza, e definindo competências, prazos e previsão de recursos a serem empregados.

\section{Referências}

ASPO - PORTUGAL. Site da ASPO Portugal Associação para o Estudo do Pico do Petróleo e do Gás. Disponível em: <http://www.aspo-portugal. net/hubbertpeak.shtml> Acesso em: 21 set. 2012.

CIC;PREFEITURA GARIBALDI. Balanço Econômico de Garibaldi 2014. 15 ${ }^{a}$ edição - dados referentes ao ano de 2013.

GARIBALDI. Estudos para o Plano Diretor de Garibaldi - Relatório Técnico. Constance Manfredini (org.). Garibaldi, 2008.

ICLEI - Conselho Internacional para as Iniciativas Locais. Towards Urban Resilience. Iclei Briefing Sheet, Maio 2011. Disponível em: <http://www. scribd.com/doc/80629381/Briefing-Sheet-UrbanResilience-20110616 > Acesso em: 19 ago. 2012. 
IBGE. Instituto Brasileiro de Geografia e Estatística. Censo Demográfico 2010 - Resultados do Universo. Disponível em: <http://www.censo2010.ibge.gov. $\mathrm{br} /$ sinopse/index . php ? uf $=43 \&$ dados $=1>$ Acesso em: 16 jul. 2012.

NEWMAN, P; BEATLEY, T.; BOYER, H. Resilient Cities: responding to peak oil and climate change. Washington DC: Islando Press, 2009.

PRASAD, N.; RAHGHIERI, F.; SHAH, F.; TROHANIS, Z.; KESSLER, E.; SINHA, R. Climate Resilient Cities - a primer on reducing vulnerabilities to disasters. Washington:The World Bank, 2009.

ROAF, S.; FUENTES, M.; THOMAS, S. Ecohouse: a casa ambientalmente sustentável. 3ed. Porto Alegre:Bookman, 2009.

SANTOS, F. T. Resiliência Estratégica para um Desenvolvimento Regional Sustentável. In: Revista Portuguesa de Estudos Regionais. n.20., 2010. Disponível em: <http://www.apdr.pt/siteRPER/PT/ revista.html > Acesso em: 17 ago. 2012.

SANTOS, F. T. Territórios Resilientes enquanto Orientação de Planeamento. In: Prospectiva e Planeamento. Vol. 16, 2009. Disponível em: $<$ http://www.dpp.pt/Lists/Pesquisa\%20Avanada/ Attachments/1426/Territorios_Resilientes.pdf> Acesso em: 17 ago. 2012.

SATTERTHWAITE, D. What Role for Low-income Communities in Urban Areas in Disaster Risk Reduction? ISDR, IIED, 2011. Disponível em: < http://www.preventionweb.net/english/hyogo/ gar/2011/en/bgdocs/Satterthwaite_2011.pdf>. Acesso em: 12 set. 2012.

UN-HABITAT. Planing For Climate Change - A Strategic, Values-Based Approach For Urban Planners. EcoPlan International, 2011. Disponível em: <http://www.unhabitat.org/pmss/listltemDetails. aspx?publicationID=3164 > Acesso em: 12 set 2012.

UNISDR - The United Nations Office for Disaster Risk Reduction. Terminology on Disaster Risk Reduction. Geneva. 2009. Disponível em: <http://www.unisdr. org/files/7817_UNISDRTerminologyEnglish.pdf> Acesso em: 14 out. 2012.

WORLD ECONOMIC FORUM. Global Risks 2015 - 10th Edition. Insight Report. 2015. Disponível em: http://reports.weforum.org/global-risks-2015/ Acesso em: 24 fev. 2015. 